\title{
Recovery of furfural and acetic acid from wood hydrolysates in biotechnological downstream processing
}

\author{
Nadia Galeotti ${ }^{1}$, Fabian Jirasek ${ }^{1}$, Jakob Burger ${ }^{2, *}$, Hans Hasse ${ }^{1}$ \\ ${ }^{1}$ Laboratory of Engineering Thermodynamics (LTD), University of Kaiserslautern, Erwin-Schrödinger Straße 44, \\ 67663 Kaiserslautern, Germany \\ ${ }^{2}$ Chair for Chemical Process Engineering, Technical University of Munich, Campus Straubing for Biotechnology \\ and Sustainability, 94315 Straubing, Germany \\ *Correspondence: Jakob Burger (E-mail: pierrette.burger@tum.de), Chair for Chemical Process Engineering, \\ Technical University of Munich, Campus Straubing for Biotechnology and Sustainability, 94315 Straubing, \\ Germany
}

\section{Abstract}

Wood hydrolysates contain sugars that can be used as feedstock in fermentation processes. For that purpose, the hydrolysate must be concentrated and inhibitors that harm the fermentation must be removed. In the present work, the integration of these tasks with the recovery of inhibitors is studied. The wood hydrolysate is represented as a quaternary mixture of (water + xylose + acetic acid + furfural). Acetic acid and furfural are two frequently occurring inhibitors. As they are also valuable chemicals, their recovery is studied. For the concentration and detoxification evaporation is used. Furfural is recovered from the vapors by heteroazeotropic distillation. It is shown that this can be achieved without additional energy. Also the recovery of acetic acid by distillation is possible, but not attractive. The new process is simulated using a thermodynamic model that was developed recently in our group and is based on comprehensive experimental data on the relevant mixtures.

Keywords: acetic acid, furfural, heteroazeotropic distillation, wood hydrolysates

\section{Introduction}

The production of chemicals, polymers, and fuels from biomass is becoming increasingly important [1-3]. One of the most widely used biomass feedstock is lignocellulosic biomass. It is available e.g. in large amounts in the pulp and paper industry. Hydrolysates of lignocellulosic biomass contain sugars that can be used in fermentations which yield desired products such as ethanol [4-8]. However, the raw hydrolysates are not suited for the fermentation, firstly because the sugar concentration is too low, and secondly because they contain components that are toxic for the microorganisms, the so-called inhibitors. These inhibitors stem from the degradation of lignin and sugars in the pulping and pre-pulping operations. Some of the major inhibitors are carboxylic acids (mainly formic acid and acetic acid), furfural, and 5-hydroxymethylfurfural $[9,10]$. Several detoxification methods are used

Received: May 25, 2018; revised: August 30, 2018; accepted: September 03, 2018

This article has been accepted for publication and undergone full peer review but has not been through the copyediting, typesetting, pagination and proofreading process, which may lead to differences between this version and the final Version of Record (VOR). This work is currently citable by using the Digital Object Identifier (DOI) given below. The final VoR will be published online in Early View as soon as possible and may be different to this Accepted Article as a result of editing. Readers should obtain the final VoR from the journal website shown below when it is published to ensure accuracy of information. The authors are responsible for the content of this Accepted Article.

To be cited as: Chem. Eng. Technol. 10.1002/ceat.201800258

Link to final VoR: https://doi.org/10.1002/ceat.201800258

This article is protected by copyright. All rights reserved. 
for removing these inhibitors, in particular: evaporation, solvent extraction, adsorption, anion-exchange $[9,11-13]$. Some of the inhibitors, e.g. acetic acid and furfural, are valuable chemicals, so that it is principally interesting to recover them in high yield and purity $[8,12$, 14]. One option to recover furfural is the use of heteroazeotropic distillation $[12,14,15]$. In this work, it is studied how furfural and acetic acid can be recovered from the hydrolysate by heteroazeotropic distillation and how this can be combined suitably with increasing the sugar concentration by evaporation. A model mixture representing the hydrolysate is studied: the quaternary mixture (water $(W)+$ xylose $(X)+$ acetic acid $(A A)+$ furfural $(F)$ ). $A$ thermodynamic model of that mixture was recently developed in our group based on comprehensive experimental data on the relevant mixtures [16]. It is used here as basis for process simulations. Water and furfural have a miscibility gap. Therefore, the model describes not only the vapor-liquid equilibrium (VLE) but also the liquid-liquid equilibrium (LLE) and the vapor-liquid-liquid equilibrium (VLLE). A new process is proposed that combines evaporation for the concentration step with a heteroazeotropic distillation for recovering furfural. No additional energy is needed for the furfural recovery. The recovery of acetic acid by distillation is possible, but not attractive.

\section{Process description}

A scheme of the proposed process for the simultaneous concentration and detoxification of the hydrolysate and the recovery of furfural is shown in Figure 1. Here, an overview of the process is given, details are specified below. The feed (stream FEED) is a dilute aqueous solution of xylose containing also some acetic acid and furfural and represents the raw hydrolysate. The xylose concentration is increased in an evaporator (EVAP) which operates at $20.0 \mathrm{kPa}$ in order to avoid the thermal degradation of the xylose. In this work a single evaporation step is simulated, but for energy optimization multi-effect evaporators are usually used in industrial processes. For the recovery of furfural from the vapor stream from the evaporator (Stream $\mathrm{V}$ ) a heteroazeotropic distillation is used. The distillation is also carried out at $20.0 \mathrm{kPa}$ to facilitate the integration with the evaporator. Lower pressures are undesired as they would increase the volumetric gas flow, which is already comparatively large for $20 \mathrm{kPa}$. Higher pressures would result in the need for a compressor as the gas leaving the evaporator is directly fed to the bottom of the distillation column (COL). Hence, the distillation column has only a rectifying section and no stripping section. It also has no reboiler. The distillate stream at the top of the distillation column (Stream $D$ ) has almost the composition of the heteroazeotrope in the system (W + F). It is condensed and then split in the decanter (DEC) into two liquid phases: the water-rich phase is recycled to the distillation column (Stream $R$ ) while the other phase, which is rich in furfural, is the product (Stream P). At the bottom of the distillation column, a dilute aqueous solution of acetic acid is obtained (Stream B). This process is called "furfural recovery process" in the following.

In a variant of this process that is shown in Figure 2, also the acetic acid is recovered. For this purpose, a liquid side stream (Steam S) is drawn from the distillation column: the water leaves the column mostly through this side stream, which additionally contains traces of furfural and acetic acid. The bottom stream is acetic acid of high purity. The furfural-rich top product is basically unchanged compared to the process discussed above. This process is called "furfural and acetic acid recovery process" in the following.

\section{Thermodynamic model}

Figure 3 shows a scheme of the model of the vapor-liquid-liquid equilibrium (VLLE) of the system (W $+X+A A+F)$. Xylose is present only in the liquid phases. The non-ideality of the liquid phases is described with the NRTL model [17]. The dimerization of acetic acid is considered only in the vapor

This article is protected by copyright. All rights reserved. 
phase, which is ideal regarding the physical interactions. The NRTL parameters resulting from the model are reported in Table 1. The parameters and the correlation of the pure component vapor pressures used in the model are reported in Table 2. The dimerization reaction of acetic acid in the vapor phase is considered as equilibrium reaction with:

$$
K^{\mathrm{D}}=\frac{y_{\text {dimer }}}{\left(y_{\text {monomer }}\right)^{2}}=\exp (-19.1001+7928.7 /(T / \mathrm{K}))
$$

Therein, $y_{\text {dimer }}$ and $y_{\text {monomer }}$ denote the vapor phase mole fractions of acetic acid monomer and dimer, respectively. More information on the model and comparisons with experimental data are given in [16]. All simulations of the present work are based on this model.

As a basis for the process design, the residue curve map for the ternary system ( $W+A A+F)$ at 20.0 $\mathrm{kPa}$, as calculated using the thermodynamic model, is shown in Figure 4. It also includes information on the LLE at $298.15 \mathrm{~K}$ and 1 bar. The calculations were performed using the software Aspen Plus [18]. The residue curves map of the ternary system has only a single distillation region. All residue curves start from the binary azeotrope $(W+F)$ and end in the pure furfural. Hence, furfural is the global high boiler, the azeotrope $(\mathrm{W}+\mathrm{F})$ is the global low boiler, acetic acid and water are saddle points, where water is more volatile than acetic acid. The feed stream of the distillation column is water-rich and contains only small amounts of acetic acid and furfural. Therefore, pure furfural is not obtained in the bottom of the distillation column but rather a water-rich stream, whereas at the top of the column, the low-boiling azeotrope $(W+F)$ is obtained. Upon condensation it splits up into two phases. The furfural-rich phase is withdrawn, the other phase is used as reflux. The bottom product lies on the $(W+A A)$ side of the phase diagram shown in Figure 4 and is found from the feed and the top-product using a material balance. In the furfural and acetic acid recovery process the side draw has to be added to the material balance.

\section{Process model and simulation procedure}

The simulation of the two process variants, the furfural recovery process (Figure 1 ) and the furfural and acetic acid recovery process (Figure 2), is based on the equilibrium stage model. The evaporator, the condenser, and the reboiler (if present) were simulated as individual equilibrium stages. The condenser is a total condenser.

In the furfural recovery process (Figure 1) the distillation column has one degree of freedom, namely the number of stages $N$ (heteroazeotropic distillation, no stripping section, no reboiler, for given feed stream and pressure). Hence, the furfural recovery depends only on the number of stages in the column. This dependency is shown in Figure 5 for a typical column feed. It shows hardly any change in the furfural recovery for $N \geq 6$. For a safety margin, the number of equilibrium stages of the distillation column was chosen to be $N=8$ here. The operating point is discussed in the next section.

In the furfural and acetic acid recovery process (Figure 2 ) the distillation column has five degrees of freedom (heteroazeotropic distillation, stripping and rectifying section, reboiler, side draw, for given feed stream and pressure). The five degrees of freedom are the number of stages in the rectifying and stripping section, the side draw position, the side draw flow rate, and the reboiler duty. The rectifying section of the column shown in Figure 2 is essentially the same as the one of the column shown in Figure 1. The water-rich liquid side draw is taken from the stage on which the gaseous feed enters, which is also similar to the process shown in Figure 1. The position of the side draw was found to be optimal at the height of the feed in preliminary simulations. But in the process shown in Figure 2, a large number of stages is needed in the stripping section of the column to achieve the desired purity of acetic acid. The column design was carried out following the idea of the $N$ - $Q$ curve as proposed in [19]. The $N$ - $Q$ curve is reported in Figure 6 and it leads to: total number of equilibrium stages $N=28$, feed position and side draw position $N_{F}=N_{S}=20$ counting from the bottom. In the 
design, a compromise between the number of stages and the reboiler duty is made. The operating point is discussed in the next section.

The simulations were carried out with Aspen Plus [18]. The evaporation enthalpies and the heat capacities of the pure components were obtained from the databank APV86.PURE32 included in Aspen Plus.

\section{Results and discussion}

The stream table and heat duties for the design point of the furfural recovery process (Figure 1) are presented in Tables 3 and 5, the corresponding results for the furfural and acetic acid recovery process (Figure 2) are presented in Tables 4 and 5. Feed stream and specifications are in the range that is interesting for industrial applications.

The feed stream (FEED) of the process is an aqueous xylose solution with a molarity of xylose of $80 \mathrm{~g}$ $\mathrm{L}^{-1}$ that also contains acetic acid and furfural in low concentration (mass fractions: $0.029 \mathrm{~g} \mathrm{~g}^{-1}$ furfural and $0.012 \mathrm{~g} \mathrm{~g}^{-1}$ acetic acid). The feed flow rate was chosen to be $2000 \mathrm{~kg} \mathrm{~h}^{-1}$. The concentration step should yield a xylose concentration of at least $300 \mathrm{~g} \mathrm{~L}^{-1}$. In the present design, the evaporation rate is $70 \%$ of the feed stream, leading to a xylose concentration of $309 \mathrm{~g} \mathrm{~L}^{-1}$ in Stream L. At the chosen pressure of $20.0 \mathrm{kPa}$ the temperature in the evaporator is then $344 \mathrm{~K}$, which is sufficiently low to prevent thermal degradation of the xylose.

In the partial evaporation the mass fractions of furfural is reduced from $0.029 \mathrm{~g} \mathrm{~g}^{-1}$ in the feed to $0.005 \mathrm{~g} \mathrm{~g}^{-1}$ in Stream L. The feed contains $58 \mathrm{~kg} \mathrm{~h}^{-1}$ furfural, of which $55.95 \mathrm{~kg} \mathrm{~h}^{-1}$ are evaporated, corresponding to $96.5 \%$. For acetic acid, the results are less favorable: the mass fraction in the feed is $0.012 \mathrm{~g} \mathrm{~g}^{-1}$ and it increases even slightly upon the partial evaporation to $0.014 \mathrm{~g} \mathrm{~g}^{-1}$. Nevertheless, from the $24 \mathrm{~kg} \mathrm{~h}^{-1}$ acetic acid in the feed, $16.78 \mathrm{~kg} \mathrm{~h}^{-1}$ are evaporated, corresponding to $69.9 \%$.

The concentrations of both acetic acid and furfural in the Stream $L$ are above the levels that are typically accepted for the fermentation such that additional detoxification steps are needed. These detoxification steps are, however, facilitated by the substantial removal of furfural and acetic acid in the evaporation.

The evaporation unit is the same for both processes discussed here.

In the furfural recovery process (Figure 1, Tables 3 and 5), furfural is recovered with a purity of almost $0.95 \mathrm{~g} \mathrm{~g}^{-1}$ (Stream P). The remaining $0.05 \mathrm{~g} \mathrm{~g}^{-1}$ are basically water, only traces of acetic acid are found. The furfural losses in distillation column are about $9 \mathrm{~kg} \mathrm{~h}^{-1}$, which is due to the absence of a stripping section. Nevertheless, the overall furfural recovery rate of the process (including the evaporation and the distillation) is almost $80 \%$. The bottom stream of the distillation is water with a purity of $0.98 \mathrm{~g} \mathrm{~g}^{-1}$, the rest being furfural and acetic acid. In the process heat is only supplied to the evaporator. The heat duty for the single effect system studied here is about $960 \mathrm{~kW}$. The distillation column required for the recovery of furfural is a small distillation column with just 8 equilibrium stages and without stripping section. The heat duty is zero; there is no additional operational expenditure. The low capital expenditure for the small column and the fact that furfural is a valuable chemical make the new "furfural recovery process" economically attractive.

In contrast, in the furfural and acetic acid recovery process (Figure 2, Tables 4 and 5) not only the 960 kW for the evaporation are needed but additionally $2330 \mathrm{~kW}$ for the reboiler. The amount of acetic acid that is recovered is only $9 \mathrm{~kg} \mathrm{~h}^{-1}$, corresponding to an overall recovery rate of acetic acid of about $40 \%$. There are only minor changes regarding the furfural recovery as compared to the simple process discussed above. This shows that the acetic acid recovery by distillation is feasible, but completely unattractive. 


\section{Conclusions}

In the present work the integration of the concentration and detoxification of wood hydrolysates by evaporation with the recovery of the valuable inhibitors furfural and acetic acid by distillation is studied. Computer simulations are carried out for the quaternary system $(W+X+A A+F)$ that is chosen to represent the hydrolysate. It is shown that it is possible to recover furfural by heteroazeotropic distillation without having to use additional energy compared to the single evaporation step, because also without the recovery of furfural the vapor from the evaporator would have to be condensed. Also the recovery of acetic acid by distillation is possible, but the process is economically not attractive.

The simulations of the present work are based on a thermodynamic model of the system $(W+X+A A$ $+F)$ that was thoroughly tested in a previous work of our group [16]. However, the studied mixture is only a model system; real hydrolysates contain many additional components. Additional experimental studies with real hydrolysates should be carried out to validate the process concept. Furthermore, there is some arbitrariness in the specifications of the feed and the product purity that were used for the present case study. Additional simulations were carried out which show that the design is feasible and robust for a wide range of choices of these parameters. The energy demand of the process can be reduced by using multiple effects for the evaporation. This has important consequences for the integration of the furfural recovery, as less steam is available. Using the model presented here, also these options can be studied easily.

\section{Acknowledgment}

The research project has received funding from the European Community's Framework Programme for Research and Innovation Horizon 2020 (2014-2020) under grant agreement n. 636077.

\section{Symbols used}

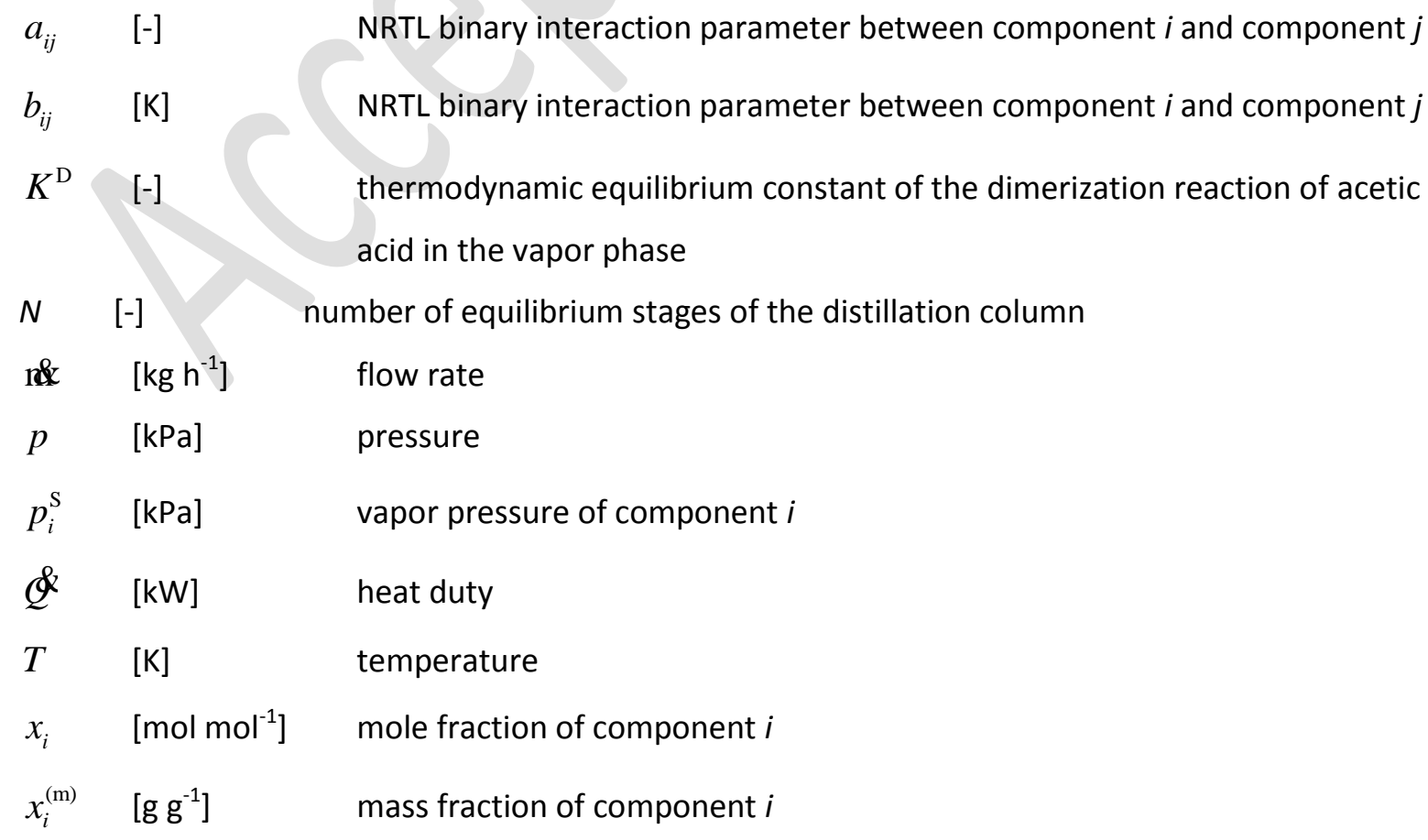

This article is protected by copyright. All rights reserved. 


\section{Greek letter}

$\alpha_{i j} \quad[-] \quad \quad$ NRTL non randomness parameter between component $i$ and component $j$

\section{Abbreviations}

$\begin{array}{ll}\text { AA } & \text { acetic acid } \\ \text { B } & \text { bottom stream } \\ \text { COL } & \text { distillation column } \\ \text { D } & \text { distillate stream } \\ \text { DEC } & \text { decanter } \\ \text { F } & \text { furfural } \\ \text { L } & \text { liquid stream exiting the evaporator } \\ \text { NRTL } & \text { Non-Random-Two-Liquid activity coefficient model } \\ \text { P } & \text { product stream } \\ \text { R } & \text { reflux stream } \\ \text { S } & \text { side draw } \\ \text { V } & \text { vapor stream exiting the evaporator } \\ \text { X } & \text { xylose } \\ \text { W } & \text { water }\end{array}$

This article is protected by copyright. All rights reserved. 


\section{References}

[1] F. Cherubini, Energy Convers. Manage., 2010, 51, 1412-1421.

DOI: 10.1016/j.enconman.2010.01.015

[2] G. W. Huber, A. Corma, Angew. Chem., 2007, 46, 7184-7201.

DOI: 10.1002/anie.200604504

[3] J. Burger, E. Ströfer, H. Hasse, Chem. Eng. Technol., 2016, 39 (2), 219-224. DOI: $10.1002 /$ ceat.201500196

[4] F. H. Isikgor, C. R. Becer, Polym. Chem., 2015, 6, 4497-4559. DOI: 10.1039/c5py00263j

[5] M. Valdivia, J. L. Galan, J. Laffarga, J.-L. Ramos, Microb. Biotechnol., 2016, 9, 585-594. DOI: 10.1111/1751-7915.12387

[6] A. Limayern, S. C. Ricke, Prog. Energy Combust. Sci., 2012, 38, 449-467. DOI: 10.1016/j.pecs.2012.03.002

[7] L. Olsson, B. Hahn-Hägerdal, Enzyme Microb. Technol., 1996, 18 (5), 312-331. DOI: 10.1016/0141-0229(95)00157-3

[8] J.- P. Lange, E. van der Heide, J. van Buijtenen, R. Price, ChemSusChem, 2012, 5 (1), 150166. DOI: $10.1002 /$ cssc. 201100648

[9] L. J. Jönsson, B. Alriksson, N.- O. Nilvebrant, Biotechnol. Biofuels, 2013, 6 (16), 1-10. DOI: 10:1186/1754-6834-6-16

[10] E. Palmqvist, B. Hahn-Hägerdal, Bioresour. Technol., 2000, 74, 17-24. DOI: 10.1016/S0960-8524(99)00160-1

[11] S. Larsson, A. Reimann, N.- O. Nilvebrant, L. J. Jönsson, Appl. Biochem. Biotechnol., 1999, 77(1), 91-103. DOI: 10.1385/ABAB:77:1-3:91

[12] C. Vila, V. Santos, J. C. Parajó, Bioresour. Technol., 2003, 90, 339-344. DOI: $10.1016 /$ S0960-8524(03)00030-0

[13] A. K. Chandel, S. S. de Silva, O. V. Singh, InTech (Ed.), 2011, Ch. 10, pp. 225-246. DOI: $10.5772 / 16454$

[14] L. Fele, V. Grilc, J. Chem. Eng. Data, 2003, 48, 564-570 . DOI: 10.1021/je020117y

[15] S. Yi, X. Qingruo, W. Tengyou, T. Zhangfa, CIESC J., 2011, 62 (7), 1800-1807. DOI:10.3969/j.issn.0438-1157.2011.07.003

[16] N. Galeotti, Ph. D. Thesis, Technical University of Kaiserslautern 2019. 
[17] H. Renon, J. M. Prausnitz, AlChE J., 1968, 14(1), 135-144. DOI: 10.1002/aic.690140124

[18] Aspen Technology, Inc., aspen Plus v8.6 - aspenONE

[19] S. Zeck, Chem. Ing. Tech., 1990, 62, 707-717. DOI: 10.1002/cite.330620904 


\section{Tables}

Table 1: NRTL parameters used in this work, $\tau_{i j}=a_{i j}+b_{i j} /(T / K) .[16]$

\begin{tabular}{lccccc}
\hline $\boldsymbol{i}+\boldsymbol{j}$ & $\boldsymbol{a}_{i j}$ & $\boldsymbol{b}_{i j} / \boldsymbol{K}$ & $\boldsymbol{a}_{j i}$ & $\boldsymbol{b}_{j i} / \boldsymbol{K}$ & $\boldsymbol{\alpha}_{i j}=\boldsymbol{\alpha}_{j i}$ \\
\hline $\mathrm{W}+\mathrm{X}$ & 1.29480 & 0.000 & -1.54200 & 0.000 & 0.30 \\
$\mathrm{~W}+\mathrm{AA}$ & -11.3771 & 4318.650 & 7.29431 & -2532.240 & 0.47 \\
$\mathrm{~W}+\mathrm{F}$ & 3.75496 & -55.438 & -3.21520 & 1221.700 & 0.30 \\
$\mathrm{X}+\mathrm{AA}$ & 3.41027 & 0.000 & 2.24623 & 0.000 & 0.47 \\
$\mathrm{X}+\mathrm{F}$ & 3.17074 & 0.000 & 6.5171 & 0.000 & 0.30 \\
$\mathrm{AA}+\mathrm{F}$ & 0.67716 & 0.000 & 0.00045 & 0.000 & 0.47 \\
\hline
\end{tabular}

Table 2: Parameters of the correlation of the pure component vapor pressures. [16] $\ln \left(p_{i}^{\mathrm{S}} / \mathrm{kPa}\right)=A_{i}+B_{i} /(T / \mathrm{K})+\mathrm{C}_{\mathrm{i}} \cdot \ln (T / \mathrm{K})+D_{i} \cdot(T / \mathrm{K})^{E}{ }_{i}$

\begin{tabular}{llrccl}
\hline$i$ & $A_{i}$ & $B_{i}$ & $C_{i}$ & $D_{i}$ & $E_{i}$ \\
\hline W & 73.649 & -7258.2 & -7.3037 & $0.41653 \mathrm{E}-05$ & 2 \\
AA & 53.270 & -6304.5 & -4.2985 & $0.88865 \mathrm{E}-17$ & 6 \\
F & 94.570 & -8372.1 & -11.1300 & $0.88150 \mathrm{E}-02$ & 1 \\
\hline
\end{tabular}


Table 3: Simulation results for the stream table of the furfural recovery process. The number of equilibrium stages of the distillation column is $\mathbf{N}=\mathbf{8}$.

\begin{tabular}{|c|c|c|c|c|c|c|}
\hline \multirow[t]{2}{*}{ Stream } & \multirow{2}{*}{$\begin{array}{l}T \\
/ \mathrm{K}\end{array}$} & \multirow{2}{*}{$\begin{array}{l}\mathrm{nd} \\
/ \mathrm{kg} \mathrm{h}^{-1}\end{array}$} & \multicolumn{2}{|c|}{$\begin{array}{l}\mathrm{r}_{i} / \mathrm{kg} \mathrm{h}^{-1} \\
x_{i}^{(\mathrm{m})} / \mathrm{g} \mathrm{g}^{-1}\end{array}$} & \multirow[b]{2}{*}{$\mathrm{AA}$} & \multirow[b]{2}{*}{$\mathrm{F}$} \\
\hline & & & $\mathrm{W}$ & $\mathrm{X}$ & & \\
\hline \multirow{2}{*}{ FEED } & \multirow{2}{*}{298.15} & \multirow{2}{*}{2000.000} & 1774.000 & 142.000 & 24.000 & 58.000 \\
\hline & & & 0.887 & 0.071 & 0.012 & 0.029 \\
\hline \multirow{2}{*}{$\mathrm{L}$} & \multirow{2}{*}{334.00} & \multirow{2}{*}{601.308} & 447.975 & 141.909 & 8.418 & 3.006 \\
\hline & & & 0.745 & 0.236 & 0.014 & 0.005 \\
\hline \multirow{2}{*}{ V } & \multirow{2}{*}{334.00} & \multirow{2}{*}{1398.690} & 1325.958 & 0.000 & 16.784 & 55.948 \\
\hline & & & 0.948 & 0.000 & 0.012 & 0.040 \\
\hline \multirow{2}{*}{ B } & \multirow{2}{*}{333.15} & \multirow{2}{*}{1350.320} & 1324.664 & 0.000 & 16.204 & 9.452 \\
\hline & & & 0.981 & 0.000 & 0.012 & 0.007 \\
\hline \multirow{2}{*}{ D } & \multirow{2}{*}{332.80} & \multirow{2}{*}{1398.760} & 1237.849 & 0.000 & 0.054 & 160.857 \\
\hline & & & 0.885 & 0.000 & $3.9 \cdot 10^{-5}$ & 0.115 \\
\hline \multirow{2}{*}{$\mathrm{R}$} & \multirow{2}{*}{298.15} & \multirow{2}{*}{1350.380} & 1235.545 & 0.000 & 0.053 & 114.782 \\
\hline & & & 0.915 & 0.000 & $3.9 \cdot 10^{-5}$ & 0.085 \\
\hline \multirow{2}{*}{$\mathrm{P}$} & \multirow{2}{*}{298.15} & \multirow{2}{*}{48.3720} & 2.515 & 0.000 & 0.001 & 45.856 \\
\hline & & & 0.052 & 0.000 & $3.1 \cdot 10^{-5}$ & 0.948 \\
\hline
\end{tabular}


Table 4: Simulation results for the furfural and acetic acid recovery process. The number of equilibrium stages of the distillation column is $N=28$, side draw location counting from bottom $=20$, feed location counting from bottom $=20$, flow rate of the side draw $n \&=$ $1333.91 \mathrm{~kg} \mathrm{~h}^{-1}, \mathcal{Q}_{\mathrm{R}}=2330.78 \mathrm{~kW}$.

\begin{tabular}{|c|c|c|c|c|c|c|}
\hline \multirow[t]{2}{*}{ Stream } & \multicolumn{2}{|r|}{$n \&$} & \multicolumn{2}{|c|}{$x_{i}^{(\mathrm{m})} / \mathrm{g} / \mathrm{g}$} & & \\
\hline & / K & $/ \mathrm{kg} \mathrm{h}^{-1}$ & $\bar{W}$ & $\bar{X}$ & $\overline{\mathrm{AA}}$ & $\bar{F}$ \\
\hline \multirow{2}{*}{ FEED } & \multirow{2}{*}{298.15} & \multirow{2}{*}{2000.000} & 1774.000 & 142.000 & 24.000 & 58.000 \\
\hline & & & 0.887 & 0.071 & 0.012 & 0.029 \\
\hline \multirow{2}{*}{$\mathrm{L}$} & \multirow{2}{*}{334.00} & \multirow{2}{*}{601.308} & 447.975 & 141.909 & 8.418 & 3.006 \\
\hline & & & 0.744 & 0.236 & 0.014 & 0.005 \\
\hline \multirow{2}{*}{ V } & \multirow{2}{*}{334.00} & \multirow{2}{*}{1398.690} & 1325.958 & 0.000 & 16.784 & 55.948 \\
\hline & & & 0.949 & 0.000 & 0.012 & 0.040 \\
\hline \multirow{2}{*}{ B } & \multirow{2}{*}{341.30} & \multirow{2}{*}{9.110} & 0.455 & 0.000 & 8.655 & 0.000 \\
\hline & & & 0.05 & 0.000 & 0.95 & 0.000 \\
\hline \multirow{2}{*}{ S } & \multirow{2}{*}{333.20} & \multirow{2}{*}{1333.910} & 1323.239 & 0.000 & 8.003 & 2.668 \\
\hline & & & 0.992 & 0.000 & 0.006 & 0.002 \\
\hline \multirow{2}{*}{ D } & \multirow{2}{*}{332.90} & \multirow{2}{*}{5006.93} & 4531.177 & 0.000 & 0.095 & 475.658 \\
\hline & & & 0.905 & 0.000 & $1.9 \cdot 10^{-5}$ & 0.095 \\
\hline \multirow{2}{*}{$\mathrm{R}$} & \multirow{2}{*}{298.15} & 1051260 & 4530.380 & 0.000 & 0.094 & 420.786 \\
\hline & & 4301.200 & 0.915 & 0.000 & $1.9 \cdot 10^{-5}$ & 0.085 \\
\hline \multirow{2}{*}{$\mathrm{P}$} & \multirow{2}{*}{298.15} & \multirow{2}{*}{55.559} & 2.889 & 0.000 & 0.001 & 52.669 \\
\hline & & & 0.052 & 0.000 & $1.5 \cdot 10^{-5}$ & 0.948 \\
\hline
\end{tabular}

Table 5: Heat duties in kW for the furfural recovery process (column 1) and for the furfural and acetic acid recovery process (column 2).

\begin{tabular}{lll}
\hline & 1 & 2 \\
\hline Evaporator & 957.46 & 957.46 \\
Condenser & 881.53 & 3212.35 \\
Reboiler & - & 2330.78 \\
\hline
\end{tabular}

This article is protected by copyright. All rights reserved. 


\section{Figure Legends}

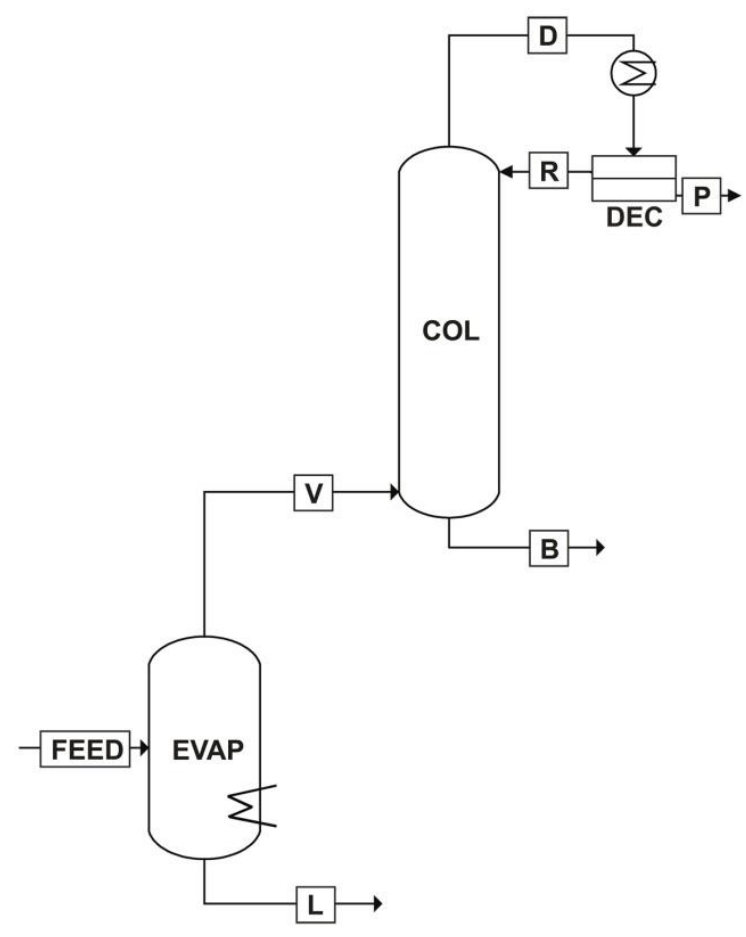

Figure 1: Process scheme of the furfural recovery process. The vapor from the evaporator is fed directly to the bottom of a rectification column, which has no reboiler.

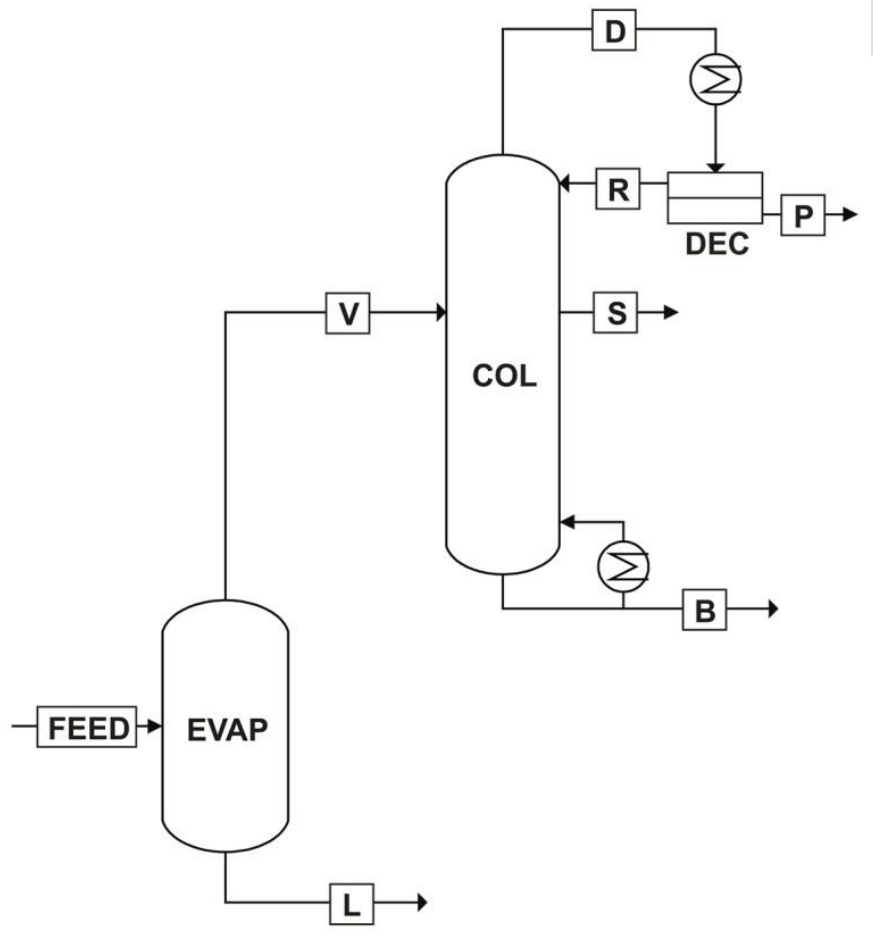

Figure 2: Process scheme of the furfural and acetic acid recovery process. 


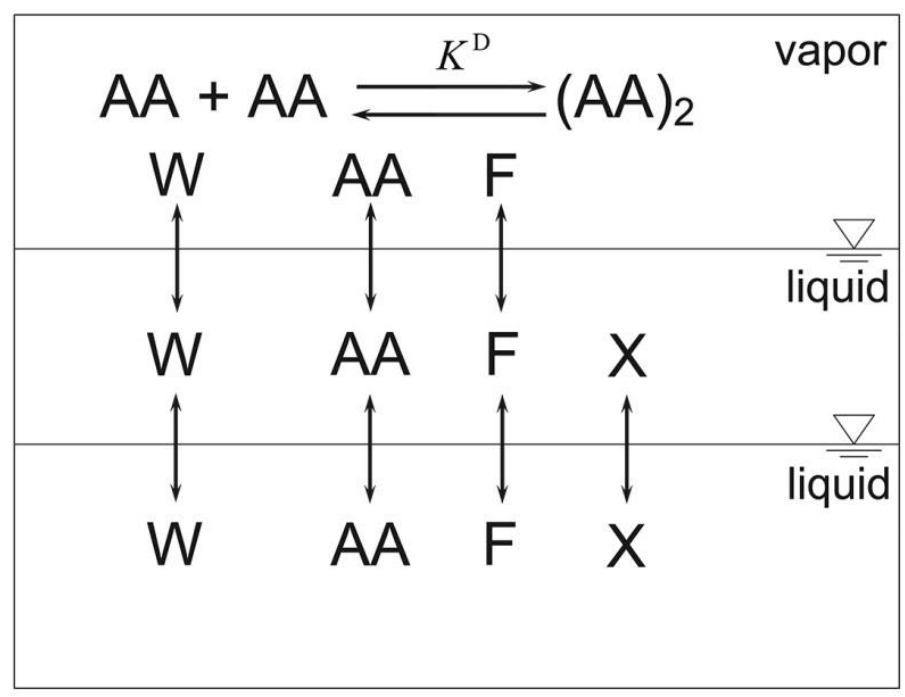

Figure 3: Scheme of vapor-liquid-liquid equilibrium of the system $(W+X+A A+F)$. The dimerization of acetic acid is considered in the gas phase only.

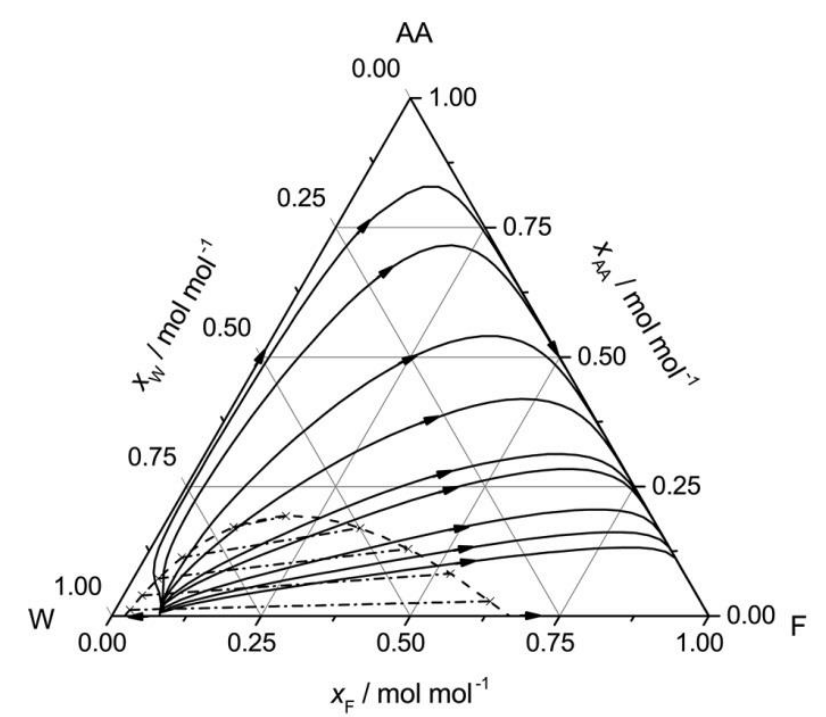

Figure 4: Residue curves map (20.0 kPa) including the liquid-liquid phase envelope (298.15 K) for the ternary system (W + AA + F): - residue curve, --- phase envelope; $x \quad x$ tie lines. 


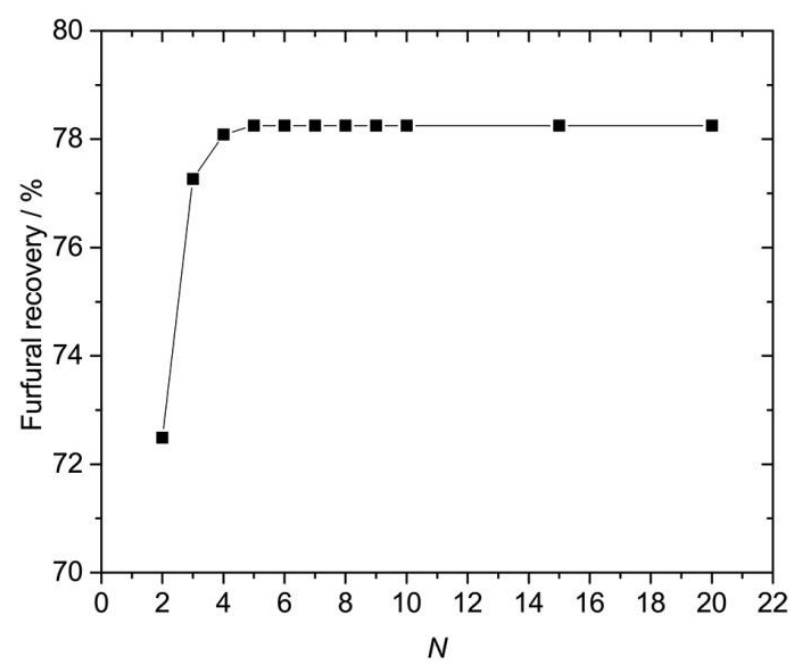

Figure 5: Furfural recovery rate in the heteroazeotropic distillation of the furfural recovery process (cf. Figure 1) as a function of the number of equilibrium stages $N(p=20 \mathrm{kPa}$, the column feed is specified in Table 3 ).

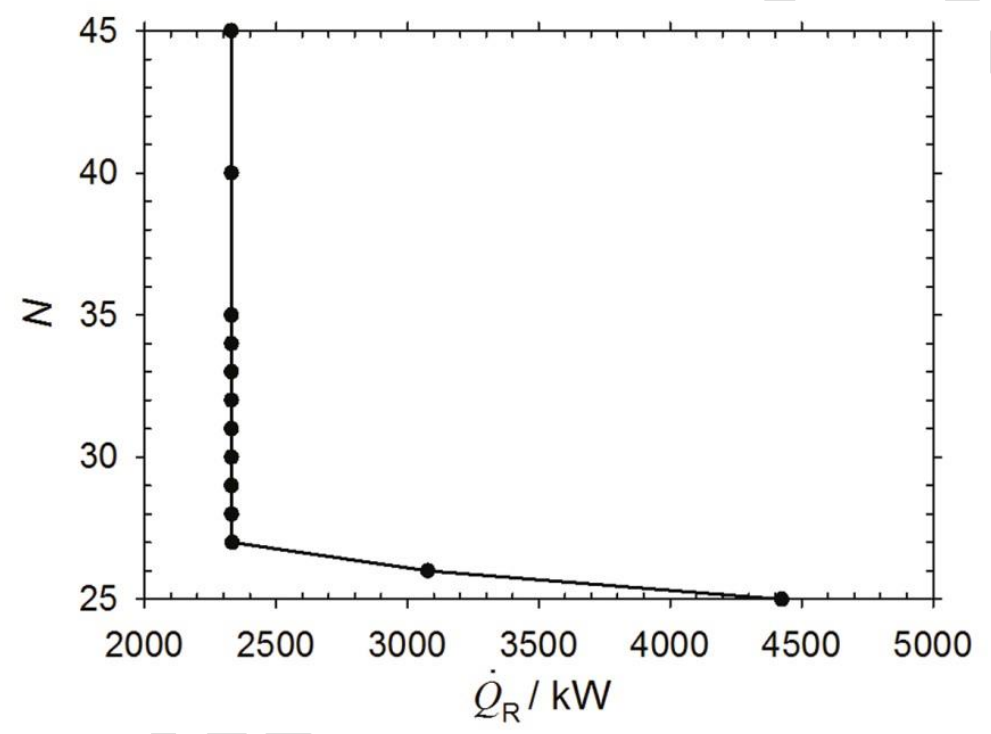

Figure 6: $N-Q$ curve for the heteroazeotropic distillation of the furfural and acetic acid recovery process (cf. Figure 2$)(p=20 \mathrm{kPa}$, the column feed is specified in Table 4$) . N$ is the total number of stages, $\&_{R}$ the reboiler duty. 
TOC

Wood hydrolysates must be concentrated and detoxified before they can be used in fermentation processes. This can be done by partial evaporation. We show that this evaporation can be integrated with a heteroazeotropic distillation to recover the important inhibitor furfural with high yield and purity without additional energy costs.
Recovery of furfural and acetic acid from wood hydrolysates in biotechnological downstream processing

N. Galeotti, F. Jirasek, J. Burger, H. Hasse

Chem. Eng. Technol. 2018, XX $(X)$,

$\operatorname{xxXX\ldots XXXX}$

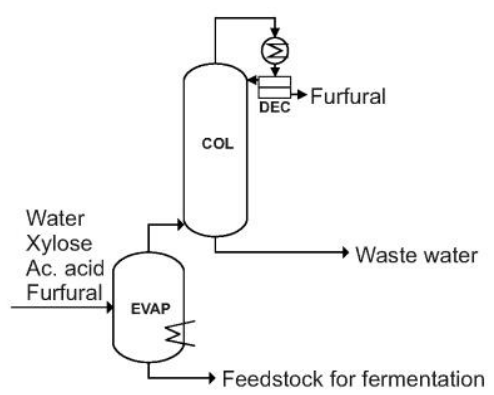

This article is protected by copyright. All rights reserved. 